
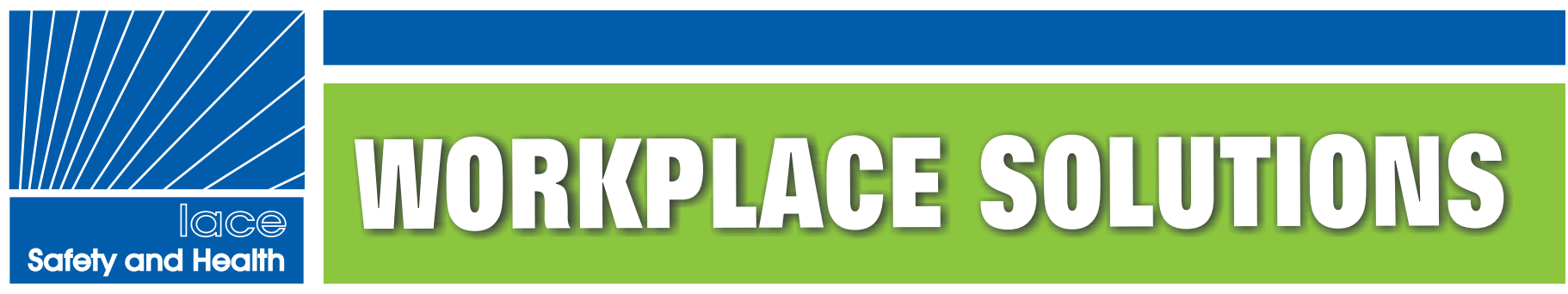

From the National Institute for Occupational Safety and Health

\title{
Preventing Worker Deaths and Injuries When Handling Micotil $300^{\circledR}$
}

\section{Summary}

Livestock producers, veterinarians, and other workers may be exposed to the toxic hazards of the animal antibiotic Micotil 300 ${ }^{\circledR}$ through needlestick injuries, skin cuts, puncture wounds, and contact with skin and mucous membranes. Cardiotoxic effects of Micotil $300^{\circledR}$ on the human heart, including a reduced cardiac contractility and tachycardia (rapid heart beat), can be severe enough to cause death.

The National Institute for Occupational Safety and Health (NIOSH) recommends that extreme care be given to following safe drug handling and injection procedures to avoid the possibility of self injection. Although no antidote exists for Micotil 300 ${ }^{\circledR}$, exposed persons should seek immediate medical intervention as the drug's cardiotoxic effects may be reversed.

\section{Description of Exposure}

Tilmicosin phosphate, sold under the trade name Micotil $300^{\circledR}$, is an animal antibiotic developed to treat "shipping fever," a bovine and ovine respiratory disease. In the United States, veterinarians give Micotil $300^{\circledR}$ to animals, but more frequently prescribe it for their clients to use on cattle and sheep at livestock facilities.

The 2002 Census of Agriculture reported 80,743 U.S. farms with cattle feed operations involving 14.9 million head of cattle [USDA 2004]. Thousands of workers on these farms could be exposed when they inject cattle with Micotil $300^{\circledR}$.

Elanco, the company that developed and produces Micotil $300^{\circledR}$, received 2,392 reports of human exposures worldwide to Micotil $300^{\circledR}$ between 1992 and 2000 [Elanco 2002]. Thirteen confirmed Micotil $300^{\circledR}$-associated human fatalities have been recorded worldwide since 1995, most associated with suicides [FDA 2006].

\section{Case Studies}

The Nebraska Fatality Assessment and Control Evaluation Program (NE FACE) investigated two separate incidents involving unintentional injection of Micotil $300^{\circledast}$.

\section{Case 1}

On March 8, 2003, a 38-year-old cattleman was preparing to inject Micotil $30{ }^{\circledR}$ into a heifer secured in a squeeze chute inside a barn. The cattleman was carrying a 12-cc plastic disposable syringe in his right hand. The man was knocked to the ground when a cow in an adjacent pen charged, striking the fence panel. As a result of either the strike or the fall, the cattleman was injected with an unknown amount of the antibiotic. He immediately began to feel dizzy and nauseated. He was able to call for help, and his wife, in the house nearby, called an ambulance. The victim was rushed to a nearby hospital where he died an hour and a half later. The death certificate indicated the cause of death was respiratory failure as a consequence of cardiac arrest caused by a lethal injection [Nebraska Department of Labor 2003].

\section{DEPARTMENT OF HEALTH AND HUMAN SERVICES \\ Centers for Disease Control and Prevention

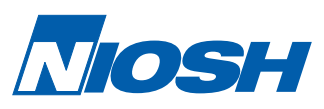




\section{Case 2}

On November 16, 2004, a 41-year-old cattle rancher was preparing to inject two calves with Micotil $300^{\circledR}$ using a 20-cc plastic disposable syringe. The calves were in an outside lot squeeze chute. After injecting the first calf, the rancher placed the syringe in his mouth to hold it, freeing his hands to open the squeeze chute gate. At the same instant, the injected calf lunged forward, flinging open the end doors and causing the handle to strike the victim's left hand, driving it backwards into the needle. The rancher was injected between his left thumb and first finger with 1 to $1.5 \mathrm{cc}$ of Micotil $300^{\circledR}$. He immediately felt a burning sensation at the injection site. Within a few minutes, he developed a severe ringing in his ears and felt as though his tongue and lips were swollen. He called out for help, and his wife called the Rocky Mountain Poison Control Center. They advised her to place ice on the injection site and immediately get her husband to an emergency room. As his condition worsened in the emergency department, he was airlifted to a regional medical center and treated in the intensive care unit for 2 days. After his condition stabilized, he was discharged [Nebraska Department of Labor 2005].

\section{Controls}

Workers and employers should take the following steps to protect themselves and others when handling or administering Micotil $300^{\circledR}$. In the case of human injection, consult a physician immediately and apply ice to the injection site. Transport the victim immediately to a hospital and call 1-800-722-0987 for further emergency information.

\section{Veterinarians}

- Consider prescribing animal medications that do not have toxic effects on humans.

- Do not administer Micotil $300^{\circledR}$ if animals cannot be restrained in an appropriate restraint, or if there is concern over operator skill.

- Using the client information sheet attached to each bottle of Micotil $300^{\circledR}$, verbally review Elanco's revised user safety warnings with each purchaser. Use a co-signed Micotil $30{ }^{\circledR}$ Client Dispensing Information form [Elanco 2006] to document that each purchaser understands that Micotil $300^{\circledR}$ has been fatal to humans. This form details the hazards associated with Micotil $300^{\circledR}$ and identifies safe administration methods, appropriate first aid treatment, and emergency phone numbers.
- Provide guidance to purchasers on proper equipment for administration. Multiple dose dispensers are available and include specific handling instructions.

\section{Employers}

Store Micotil $300^{\circledast}$ in a safe location that is not readily accessible by untrained persons.

- Train workers assigned to handle Micotil $300^{\circledR}$ by using training videos, DVDs, laminated dosage sheets, material safety data sheets (MSDS), client information sheet, and safe handling cards. To obtain these materials, call Elanco at 1-800-428-4441 or visit Elanco's Web site at www.elanco.com.

- Ensure that proper handling procedures for Micotil $300^{\circledR}$ are available at the worksite and are reviewed by all workers before they handle this drug. These procedures should be written in the primary language(s) of drug handlers and at their reading level.

- Provide a means to adequately restrain animals during treatment. An animal that is adequately restrained will not be able to move in an unpredictable manner. Work with a veterinarian to determine what adequate restraint means for the particular operation.

- Provide a sharps disposal container for safe handling and disposal of syringes and needles, and goggles and impermeable, needle-puncture-resistant gloves for personal protection.

- Ensure that only persons trained in the hazards of Micotil $300^{\circledR}$ and safe handling procedures are allowed to handle this drug and that workers do not work alone while handling or injecting the drug.

- Ensure that coldpacks and icepacks are available at the workplace where injections will be given.

Ensure that telephones are available to workers. Post the following telephone numbers in visible locations such as near the office, barn, and house telephones:

- Emergency Medical Services 911 or dial 0 (operator) and report the emergency and specific location

- Rocky Mountain Poison Control and Drug Center 1-800-332-3073 (This center has been trained by the drug manufacturer to handle emergencies specific to Micotil $300^{\circledR}$ exposure in both English and Spanish)

- Elanco: 1-800-722-0987, medical emergency hotline; 1-800-428-4441 (English only) 


\section{Workers}

\section{Drug handling and preparation}

- Read, understand, and follow all directions located on the label and on the client information sheet that is provided with each bottle of Micotil $300^{\circledR}$.

- Wear goggles and impermeable, needle-punctureresistant gloves, and wash hands after handling.

- Never work alone when handling or injecting Micotil $300^{\circledR}$.

- Fill syringes in an area restricted for that purpose alone (preparation room). Never allow children in this area.

- Do not smoke, eat, drink, or store food in the resticted area.

- Never use automatically powered syringes.

- Never fill one syringe with medication for injecting several animals. Use a separate syringe for each animal. If provided with a multiple dose dispenser, ask employer for specific handling instructions.

- Always use a 16- to 18 -gauge needle that is $1 / 2$ inch to $5 / 8$ inches long.

- Keep a protective cover on needles until ready for use.

- Place filled syringes in a puncture-proof carrying case before moving to the animal's location.

- Never place or carry a loaded syringe in a pocket, other clothing, or in the mouth.

- Clean up spills immediately.

- Call one of the emergency contact numbers if an exposure occurs, apply ice, proceed immediately to a hospital emergency room, or call 911 for emergency transport.

\section{Injection of livestock}

- Keep children and bystanders out of the area where Micotil $300^{\circledR}$ is to be given.

- Wear goggles and impermeable, needle-punctureresistant gloves, and wash hands after handling.

- Evaluate the animal to be injected as well as the animal's surroundings to determine whether it is safe to give the drug.

- Do not give the drug to an animal that cannot be adequately restrained.

- Restrain animals in a restraint that the employer, in consultation with the veterinarian, has determined is adequate for the operation.
Identify a useable exit route in case the animal breaks out of the restraint.

Inject Micotil $300^{\circledR}$ by holding the syringe in one hand while inserting the needle subcutaneously and at a top-down angle. Avoid penetrating the animal's underlying muscle.

- Do not replace the protective cap over the needle of the syringe after use.

Immediately after use, place the syringe with needle attached in a puncture-proof sharps disposal container. Return the disposal container to the preparation area for final disposal.

\section{Acknowledgments}

The principal contributors to this publication were Doloris Higgins, NIOSH Division of Safety Research; William Hetzler and Arthur Davis, Nebraska Workforce Development; Susanna Von Essen, MD, MPH, Nebraska Medical Center; Kelley Donham, DVM, MS, Professor and Associate Department Head for Agricultural Medicine, College of Public Health, University of Iowa, Great Plains Agricultural Center; Dan McChesney, Ph.D., FDA; Victoria Hampshire, VMD, FDA; John Baker, DVM, FDA.

\section{References}

Elanco [2002]. Timeline, an Elanco publication for veterinarians. Greenfield, IN: Issue no. 3, Winter 2002.

Elanco [2006]. Micotil 300® client dispensing information. Greenfield, IN: Elanco Animal Health, Form No. AI9910.

FDA [2006]. Unpublished FDA analysis of Center for Veterinary Medicine adverse drug event data base. Washington, DC: U.S. Food and Drug Administration, Center for Veterinary Medicine.

Nebraska Department of Labor [2003]. Cattleman dies due to accidental injection. Omaha, NE: Nebraska Department of Labor, Nebraska Fatality Assessment and Control Evaluation Program (NE FACE) Report No. 03NE004.

Nebraska Department of Labor [2005]. Cattle rancher hospitalized after accidental injection of Micotil. Omaha, NE: Nebraska Department of Labor, Nebraska Fatality Assessment and Control Evaluation Program (NE FACE) Report No. 04NE99.

USDA [2004]. 2002 Census of Agriculture: United States summary and State data. Volume 1. Geographical Area Series. Part S1. Washington, DC: U.S. Department of Agriculture, Agricultural Statistics Service, Report AL-02-4-51. 


\section{For More Information}

For more information about intervention after human exposure to injected Micotil $300^{\circledR}$, contact Elanco Animal Health, a Division of Eli Lilly \& Company: P.O. Box 707, 2001 W. Main St., Greenfield, IN 46140; telephone 1-800-722-0987.

For Micotil $300^{\circledR}$ safe handling and use materials, visit the Elanco Web site at www.elanco.com.

The information in this document is based on fatality investigations, literature, and expert review. More information about the Fatality Assessment and Control Evaluation Program is available at www.cdc.gov/niosh/face.

To receive documents or other information about occupational safety and health topics, contact NIOSH at

\section{NIOSH Publications}

4676 Columbia Parkway

Cincinnati, OH 45226-1998

Telephone: 1-800-35-NIOSH (1-800-356-4674)

Fax: 513-533-8573 - Email: pubstaft@cdc.gov

or visit the NIOSH Web site at www.cdc.gov/niosh

Preventing Worker Deaths and Injuries When Handling Micotil $300^{\circledR}$
- For a monthly update on news at NIOSH, subscribe to NIOSH eNews by visiting www.cdc.gov/niosh/eNews.

Mention of any company or product does not constitute endorsement by NIOSH. In addition, citations to Web sites external to NIOSH do not constitute NIOSH endorsement of the sponsoring organizations or their programs or products. Futhermore, NIOSH is not responsible for the content of these Web sites.

This document is in the public domain and may be freely copied or reprinted. NIOSH encourages all readers of the Workplace Solutions to make them available to all interested employers and workers.

As part of the Centers for Disease Control and Prevention, NIOSH is the Federal agency responsible for conducting research and making recommendations for preventing workrelated illnesses and injuries. All Workplace Solutions are based on research studies that show how worker exposures to hazardous agents or activities can be significantly reduced.

DHHS (NIOSH) Publication No. 2007-124

\section{DEPARTMENT OF HEALTH AND HUMAN SERVICES}

Centers for Disease Control and Prevention

National Institute for Occupational Safety and Health

4676 Columbia Parkway

Cincinnati, OH 45226-1998

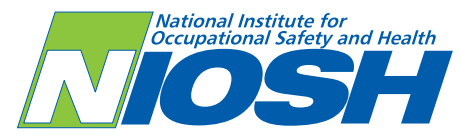

